\title{
Constitutive Modeling of Geomaterials and Interfaces with Applications
}

\author{
Rafiqul Tarefder ${ }^{1} \cdot$ Chandrakant Desai $^{1} \cdot$ Musharraf Zaman $^{1}$
}

Published online: 16 June 2017

(C) Indian Geotechnical Society 2017

This special issue contains eight papers covering the use and applications of various constitutive models in finite element moldering (FEM) framework to characterize small to large scale stress-strain behavior of geomaterials including soils, rocks, and their interfaces with structures such as in tunnels, piles and piers. The paper by Wang et al. has used an interaction model to characterize the interface between rock and tunnel to analyze the nonlinear responses of a cross-fault. Alyounis and Desai implemented the unified disturbed state concept, DSC, developed previously by Desai (2001) in a dynamic finite element modeling framework with and without interfaces to study behavior of pile including liquefaction. Borana et al. has shown how stress state variables such as mastic suction and roughness affect shearing behavior of interfaces. Yang and Carter presented the theory of isotach elastoplasticity in capturing the strain rate and time effects on the mechanical behavior of clayey soil. Courtney and Tarefder evaluated four different material models: soil and foam pressure dependent strength model, the pseudo tensor pressure dependent strength model, the Drucker-Prager model, and the twoinvariant geologic cap model in LS-DYNA using MultiMaterial Arbitrary Lagrangian-Eulerian (MM-ALE) methods to simulate explosively-induced airblast loads in cohesive soils. Huang et al. has shown that the failure pattern and strength of rock sample are greatly influenced by the size of mesh and sample height. Cividini and Gioda have shown a calibration procedure of an elastic-plastic constitutive model and its implementation in FEM framework in the study of pier foundation. Prashant et al. has determined shear stiffness modulus of fill materials using bender elements in 3D FEM framework using ABAQUS.

Rafiqul Tarefder

tarefder@unm.edu

1 Albuquerque, NM, USA 